\title{
THE ASSOCIATION OF PARTICULAR TYPES OF PROTEUS WITH CHRONIC SUPPURATIVE OTITIS MEDIA
}

\author{
B. W. Senior and G. Sweeney*
}

Department of Bacteriology, The University of Dundee Medical School, Ninewells Hospital, Dundee DDI 9SY and *Department of Bacteriology, Glasgow Royal Maternity Hospital, Glasgow G4 ONA

\begin{abstract}
Summary. During a period of 12 months, 57 strains of Proteus were isolated from the ears of 38 unrelated patients with chronic suppurative otitis media. Each strain was identified, typed for bacteriocin production and sensitivity, and tested for Dienes compatibility. The majority of the strains $(79 \%)$ were $P$. mirabilis; all but one of the remainder were $P$. vulgaris. Although 19 different bacteriocin production/sensitivity types were found, two rare types, $P$. mirabilis $\mathrm{P} 7 / \mathrm{S} 5,12$ and $P$. vulgaris $\mathrm{P} 0 / \mathrm{S} 9$, were associated with $47 \%$ of these infections. This was confirmed by Dienes typing.

Patients with bilateral ear disease carried a different strain in each ear. There was no evidence that persistence of infection had arisen because of the development of antibiotic resistance. Although there was some evidence that persistence may have been the result of reinfection, the isolation of these rare types of Proteus from so many patients with chronic suppurative otitis media may indicate that they play an important role in the pathogenesis of the disease. Most of the Proteus isolates were of "non-faecal" types and it is believed that infection had arisen by a route other than the faecal-aural one.
\end{abstract}

\section{INTRODUCTION}

Chronic suppurative otitis media (CSOM) is an insidious, persistent and progressively destructive disease with irreversible sequelae. It is widely accepted that bacteria play a secondary role in its pathogenesis but strains of Proteus and Pseudomonas are often found as the dominant aerobes (Palva and Hallstrom, 1965; Brook and Finegold, 1979; Constable and Butler, 1982). This is somewhat surprising because an obvious source of infection in patients with perforated tympanic membranes is the oropharynx and these organisms are only transient members of the oral flora in healthy subjects. In a 3-year survey of 2470 patients with chronically discharging ears, $52 \%$ were infected with Proteus strains and in one-third of these infections they were the sole infecting organisms (Rees, 1971). In a recent survey of 130 patients with CSOM, Proteus was present in large numbers $\left(10^{9}\right.$ organisms $/ \mathrm{ml}$ ) in $61 \%$ of cases (Sweeney, Picozzi and 
Browning, 1982). Attempts at eradicating infection by radical surgery are particularly unsuccessful when Proteus is the infecting organism (Ojala et al., 1981). It is now possible to distinguish one Proteus strain from another by reliable, highly discriminating techniques (Senior, 1977 $a$ and $b$ ). The aim of this study was to determine the types of Proteus strains associated with CSOM in order that the epidemiology and pathogenesis of CSOM infections with Proteus might be investigated.

\section{MATERIALS AND METHODS}

Source of bacterial strains. From October 1979 to September 1980, Proteus strains were isolated from 38 unrelated patients, 22 males and 16 females, who attended a chronic otitis media out-patient clinic held in Glasgow Royal Infirmary. The individuals, whose ages were in the range 17-77 years, had protracted histories of ear disease and presented with active CSOM; the diagnosis was based upon the secretion of copious pus in association with hyperaemia and oedema of the middle ear mucosa. None of the group had received any antimicrobial therapy in the 4 weeks preceding the hospital visit. The infected ear exudates were sampled during the patients' first visit to the clinic. From nine of the patients, ear exudate was also collected for culture after antibiotic therapy.

Isolation and identification of strains. Under direct microscopic vision, a loopful of exudate was taken through an aural speculum from one ear that showed signs of active infection in 32 patients and from both ears of six patients with bilateral disease; specimens were collected from the most clinically active site. The specimen was diluted in either sterile peptone water (Oxoid CM9) or Brain Heart Infusion broth (Oxoid CM225) and plated out on Cystine-Lactose-Electrolyte-Deficient (CLED) agar (Oxoid CM301). After overnight incubation at $37^{\circ} \mathrm{C}$ strains of Proteus were recognised as non-lactose fermenting colonies that were shown subsequently to produce phenylalanine deaminase and urease. All such strains were identified to species level by testing their ability to form indole, ornithine decarboxylase and hydrogen sulphide and produce acid in maltose and mannitol peptone water sugars. The isolates were maintained as pure cultures on nutrient agar slopes at 4 C.

Antibiotic sensitivity testing. Sensitivity to cephaloridine, cephalexin, ampicillin, gentamicin, neomycin and chloramphenicol was tested by the disk-diffusion method on Iso-sensitest agar (Oxoid CM471).

Bacteriocin typing of strains. Each strain was tested for its ability to produce a bacteriocin (proticine) active against 13 standard indicator strains, each of which was sensitive to only one of 13 different proticines - this gave the proticine-producer $(\mathrm{P})$ type of the strain - and for its sensitivity to inhibition by proticines produced by 13 standard proticine-producing strains- this gave the proticine-sensitivity (S) type of the strain. The standard strains and the typing method have been described previously (Senior, 1977a).

Dienes typing of strains. The Dienes compatibility test was applied to all strains according to methods described previously (Senior, 1977b).

\section{RESULTS}

A total of 53 ears were examined. A single Proteus strain was isolated from 49 ears and four ears were infected with two different Proteus strains. Biochemical tests on the 57 Proteus isolates showed that 45 strains were $P$. mirabilis, 11 strains were $P$. vulgaris and one strain was $P$. morgani. Of the $P$. mirabilis strains, $89 \%$ were proticinogenic. These strains produced eight different proticines of which the commonest was proticine type 7 , which was produced by $40 \%$ of the proticinogenic strains.

The 57 strains included 19 different proticine production/proticine sensitivity $(\mathrm{P} / \mathrm{S})$ types. However, $47 \%$ of the isolates belonged to only two $\mathrm{P} / \mathrm{S}$ types (figure). The commonest $\mathrm{P} / \mathrm{S}$ type was $\mathrm{P} 7 / \mathrm{S} 5,12$ (16 strains) followed by $\mathrm{P} 0 / \mathrm{S} 9$ (11 strains). All the $P$. vulgaris strains were of type $\mathrm{P} 0 / \mathrm{S} 9$. 


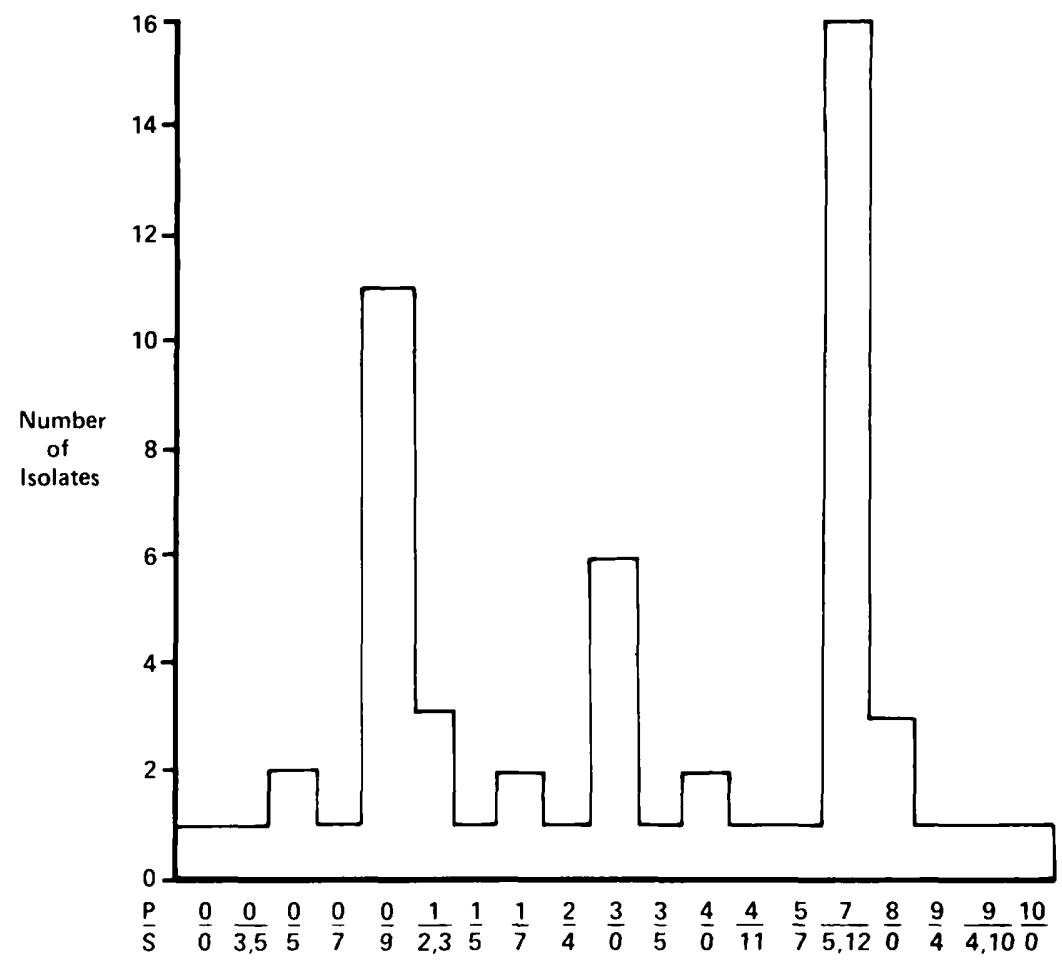

Proticine production (P) / Proticine Sensitivity (S), type of strain

FIGURE-The frequency of occurrence of the different P/S types of Proteus associated with chronic suppurative otitis media.

TABLE I

$P / S$ types of Proteus strains cultured from nine patients, before and after treatment

\begin{tabular}{|c|c|c|c|c|c|}
\hline \multirow{2}{*}{$\begin{array}{l}\text { Patient } \\
\text { no. }\end{array}$} & \multirow[b]{2}{*}{ Treatment } & \multicolumn{4}{|c|}{$\begin{array}{c}\text { Species and } \mathrm{P} / \mathrm{S} \text { type } \\
\text { of Proteus strains isolated }\end{array}$} \\
\hline & & \multicolumn{2}{|c|}{ before treatment } & \multicolumn{2}{|c|}{ after treatment } \\
\hline 1 & Dry mop & P. mirabilis* & $3 / 0$ & P. mirabilis & $8 / 0$ \\
\hline 2 & Cephalexin + Metronidazole & $P$ mirabilis & $7 / 5,12$ & P. mirabilis & $0 / 3,5$ \\
\hline 3 & Dry mop & P. vulgaris & $0 / 9$ & P. mirabilis & $3 / 5$ \\
\hline 4 & Metronidazole & $P$. vulgaris & $0 / 9$ & P. mirabilis* & $0 / 0$ \\
\hline 5 & Cephalexin & P. mirabilis & $3 / 0$ & P. mirabilis & $5 / 7$ \\
\hline 6 & Cephalexin & P. mirabilis* & $8 / 0$ & P. mirabilis* & $3 / 0$ \\
\hline 7 & Amoxycillin + Metronidazole & P. mirabilis & $7 / 5,12$ & P. mirabilis* & $0 / 5$ \\
\hline 8 & Cephalexin + Metronidazole & $P$. mirabilis & $1 / 2,3$ & P. mirabilis & $1 / 2,3$ \\
\hline 9 & Amoxycillin & P. mirabilis & $7 / 5,12$ & P. mirabilis* & $7 / 5,12$ \\
\hline
\end{tabular}

* Sole isolate from these specimens.

All the strains of type P7/S5,12 gave Dienes reactions of compatibility with each other and incompatibility with any other strain of a different P/S type. Similarly, all the strains of $\mathrm{P} / \mathrm{S}$ type $\mathrm{P} 0 / \mathrm{S} 9$ gave reactions of compatibility only with strains of the same $\mathrm{P} / \mathrm{S}$ type. The results of these two typing methods, therefore, showed that one strain of $P$. mirabilis and one strain of $P$. vulgaris contributed to $47 \%$ of the CSOM infections. 
TABLE II

Antibiotic sensitivities of the commonly isolated Proteus strains

\begin{tabular}{l|cc}
\hline $\begin{array}{c}\text { Antibiotic } \\
\text { (disk strength, } \mu \mathrm{g})\end{array}$ & $\begin{array}{c}\text { Number of strains sensitive to the antibiotic of } \\
\text { P. mirabilis P7/S5,12 } \\
(\mathrm{n}=16)\end{array}$ & $\begin{array}{c}\text { P. vulgaris P0/S9 } \\
(\mathrm{n}=11)\end{array}$ \\
\hline Cephaloridine (10) & 8 & 4 \\
Cephalexin (30) & 14 & 7 \\
Ampicillin (10) & 15 & 7 \\
Chloramphenicol (10) & 14 & 10 \\
Neomycin (10) & 15 & 10 \\
Gentamicin (10) & 16 & 11 \\
\hline
\end{tabular}

Thirteen Proteus strains, each of a different P/S type, were isolated from the 12 ears of the six patients with bilateral disease. Thus for all these patients, the strain infecting one ear was different from the strain or strains infecting the other. Analysis of the $\mathrm{P} / \mathrm{S}$ types of the strains isolated from nine patients from whom pus was taken both before and after antibiotic treatment (table I) revealed that in only two instances (patients 8 and 9) was a strain of identical P/S type isolated both before and after treatment. One of these patients had a persistent infection with type P7/S5,12.

The prevalence of the two commonest strains, $\mathrm{P} / \mathrm{S}$ types $\mathrm{P} 7 / \mathrm{S} 5,12$ and $\mathrm{P} 0 / \mathrm{S} 9$, is not the outcome of the antibiotic resistance of these strains. Antibiotic sensitivity results presented in table II show that $82 \%$ of these strains were sensitive to ampicillin and $89 \%$ to choramphenicol. All the 57 strains tested were sensitive to gentamicin.

\section{DiscusSION}

We believe that the close association found between the presence of high numbers of Proteus (Sweeney et al., 1982) and a heavy purulent discharge from the ear is an indication that these organisms have contributed to the pathological process of CSOM in spite of the fact that as many as $75 \%$ of the ears continued to discharge even after 4 weeks of appropriate systemic or topical antibiotic therapy (Browning et al., 1983). It is unlikely that persistence of the disease was the outcome of the development of antibiotic resistance by the infecting organism because the most frequently isolated strains were not unusually resistant to antibiotics (table II).

Persistence of the ear infections may arise either through failure to eliminate the original infecting strain, such as might happen if an antibiotic cannot penetrate pus, or it may be the result of reinfection with a different Proteus strain. Direct evidence for reinfection was found in seven of the nine patients who were examined before and after antibiotic therapy and who were infected with a new $\mathrm{P} / \mathrm{S}$ type after treatment. However, if reinfection is the sole cause of persistence, we would expect that strains of many more $\mathrm{P} / \mathrm{S}$ types would have been found. The finding that of the $19 \mathrm{P} / \mathrm{S}$ types of Proteus isolated, only two, $P$. mirabilis $\mathrm{P} 7 / \mathrm{S} 5,12$ and $P$. vulgaris $\mathrm{P} 0 / \mathrm{S} 9$, contributed to almost half of the ear infections, suggests that these strains may have particular virulence properties in relation to the chronically diseased ear. Further support for this suggestion comes from the finding that not one strain of P/S type P7/S5,12 was found amongst 725 strains of $P$. mirabilis isolated from the urine, faeces and purulent 
discharges from Scottish, English and Swedish individuals of both sexes and wide age span who were without ear infections (Senior, 1979; Senior and Larsson, 1983), although it was the commonest type isolated from patients with CSOM in this study.

In CSOM the primary route of entry of bacteria into the middle ear is by the faecal-aural route through the external ear canal (Fairbanks, 1981). However, $75 \%$ of the Proteus isolates in this study were not of faecal P/S types (Senior, 1979) and $P$. morgani, which is frequently found in faeces, was isolated from only one patient with CSOM. It would appear, therefore, that the route of infection in these patients is other than the faecal-aural route.

We thank Mr G. G. Browning and his colleagues in the Department of Otolaryngology, Royal Infirmary, Glasgow, for their co-operation in this study.

\section{REFERENCES}

Brook I, Finegold S M 1979 Bacteriology of chronic otitis media. Journal of the American Medical Association 241:487-488.

Browning G G, Picozzi G, Sweeney G, Calder I 1983 Role of anaerobes in chronic otitis media. Clinical Otolaryngology 8:47-51.

Constable L, Butler I 1982 Microbial flora in chronic otitis media. Journal of Infection 5:57-60.

Fairbanks D N F 1981 Antimicrobial therapy for chronic suppurative otitis media. Annals of Otology, Rhinology and Laryngology 90: suppl 84, 58-62.

Ojala K, Sorri M, Riihikangas P, Sipila P 1981 Comparison of pre- and post-operative bacteriology of chronic ears. Journal of Laryngology and Otology 95: 1023-1029.

Palva T, Hallstrom O 1965 Bacteriology of chronic otitis media. Results of analyses from the ear canal and from the operative cavity. Archives of Otolaryngology 82:359-364.

Rees T 1971 Bacteria from the chronic ear. British Journal of Clinical Practice 25:453-454.

Senior B W 1977a Typing of Proteus strains by proticine production and sensitivity. Journal of Medical Microbiology 10:7-17.

Senior B W 1977b The Dienes Phenomenon: identification of the determinants of compatibility. Journal of General Microbiology 102:235-244.

Senior B W 1979 The special affinity of particular types of Proteus mirabilis for the urinary tract. Journal of Medical Microbiology 12:1-8.

Senior B W, Larsson P 1983 A highly discriminatory multi-typing scheme for Proteus mirabilis and Proteus vulgaris. Journal of Medical Microbiology 16:193-202.

Sweeney G, Picozzi G L, Browning G G 1982 A quantitative study of aerobic and anaerobic bacteria in chronic suppurative otitis media. Journal of Infection 5:47-55. 